\title{
FERTILIZANTES NÃO CONVENCIONAIS: MATÉRIAS-PRIMAS, PROCESSOS, PRODUTOS E EFICIÊNCIA AGRONÔMICA
}

\author{
J.V.Valarelli ${ }^{1}$ \\ F.G.Rahal ${ }^{2}$ \\ E.Cekinski ${ }^{3}$ \\ C.E.Calmanovici ${ }^{3}$ \\ J.L.G.Figueira ${ }^{1}$ \\ R.Neumann ${ }^{2}$ \\ R.Guardani ${ }^{3}$
}

A maioria dos fertilizantes fosfatados produzidos e consumidos no país são obtidos através da solubilização, por ácido sulfúrico, de concentrados. Dispendem-se algumas centenas de milhões de dólares com importação de enxofre e ácido sulfúrico para esse fim. Além disso, esse processo exige concentrados de alto teor $\left(>35 \% \mathrm{P}_{2} \mathrm{O}_{5}\right)$ só possíveis de serem obtidos com técnicas de concentração de alto custo que elevam o "cut-off" do minério, além de acarretar perdas de $\mathrm{P}_{2} \mathrm{O}_{5}$ em rejeitos.

Até o presente, o Brasil tem importado todo o potássio consumido no país, seja na forma de cloreto ou de sulfato, dispendendo para isso outra centena de milhões de dolares.

O desenvolvimento de processos que evitem a evasão de divisas com importação de insumos, que empreguem tecnologia nacional e energia disponível no país (carvão vegetal ou mineral, bagaço de cana, energia elétrica) e que produzam fertilizantes de solubilidade cítrica tem sido preocupação constante dos autores.

\footnotetext{
Departamento de Mineralogia e Petrologia, Instituto de Geociências/USP, São Paulo.

2 Pós-graduação, Instituto de Geociências/USP, São Paulo.

3 IPT, São Paulo.
} 
Consideram-se também melhor aproveitamento das nossas reservas fosfáticas através da utilização de concentrados menos nobres do que os exigidos pelos processos via umida, aproveitamento de rochas potássicas e as vantagens apresentadas pelos fertilizantes insolúveis em água e solúveis em ácidos fracos quando utilizados nas nossas condições de clima e solo.

Nesse sentido foram desenvolvidos os seguintes processos de produção de fertilizantes inorgânicos:

a) Termofosfato calcinado em forno de grelha - consiste na mistura de concentrados fosfáticos com aditivos (fundentes e combustível), sua granulação (com ajuda de ácido fosfórico), secagem e calcinação em grelha $\left(1200-1300^{\circ} \mathrm{C}\right)$. Como fundentes são utilizados sílica e carbonato de sódio, e como combustível, carvão vegetal e/ou bagaço de cana peletizado.

Os produtos consistem, essencialmente, de renanita $\left(\mathrm{CaNaPO}_{4}\right)$ e andoíta $\left(\mathrm{Ca}_{5} \mathrm{Na}_{2}\left(\mathrm{PO}_{4}\right)_{4}\right)$ contendo $29,4 \% \mathrm{P}_{2} \mathrm{O}_{5}$ total e $24 \% \mathrm{P}_{2} \mathrm{O}_{5}$ solúvel em ácido cítrico, teores susceptíveis de serem aumentados (PEREIRA et al., 1988).

b) Fosfato potássio magnesiano fundido - obtido como no processo "Yoorin", por fusão $\left(1300-1400^{\circ} \mathrm{C}\right)$ de mistura de concentrado de apatita com rochas potássicas (sienitos, ardósias, xistos, etc. com grande porcentagem de feldspatos, feldspatóides ou micas potássicas, com teores superiores a $10 \% \mathrm{~K}_{2} \mathrm{O}$ ) e materiais magnesianos (peridotitos, dunitos, serpentinitos, dolomitos, magnesita, escorias).

O produto vítreo pode conter $18-20 \% \mathrm{P}_{2} \mathrm{O}_{5}$ com solubilidade cítrica acima de $80 \%, 4-5 \%$ $\mathrm{K}_{2} \mathrm{O}$ totalmente solúveis em ácido cítrico, além de elementos básicos como $\mathrm{MgO}$ e CaO.

c) Fertilizantes potássicos $\mathrm{e} \mathrm{SO}_{2}$ - consiste no tratamento térmico $\left(1100-1200^{\circ} \mathrm{C}\right)$ de mistura de rochas potássicas (alumínio-silicatos de potássio com $\mathrm{K}_{2} \mathrm{O}>10 \%$ ), gesso natural ou sintético (fosfogesso) e agente redutor, carvão vegetal ou mineral. No processo produz-se $\mathrm{SO}_{2}$ gasoso e produto sólido com 6-7\% $\mathrm{K}_{2} \mathrm{O}, 70 \%$ dos quais solúveis em água, $\mathrm{CaSiO}_{3}$ e $\mathrm{Ca}_{2} \mathrm{Al}_{2} \mathrm{SiO}_{7}$ insolúveis (matérias-primas para cimento Portland) (GUARDANI et al., 1985; VALARELLI \& GUARDANI, 1981).

d) Fertilizantes à base de fosfato de magnésio, farringtonita - consiste na reação entre rocha fosfática e a carnalita em temperaturas entre 550 e $700^{\circ} \mathrm{C}$, em forno comum. $\mathrm{O}$ magnésio da carnalita fundida substitui cálcio da apatita formando farringtonita, $\mathrm{Mg}_{3}\left(\mathrm{PO}_{4}\right)_{2}$, solúvel em ácido cítrico. Partindo-se de rochas fosfáticas com $26 \%$ de $\mathrm{P}_{2} \mathrm{O}_{5}$, foram obtidos produtos com $34 \% \mathrm{P}_{2} \mathrm{O}_{5}$ total e $21 \%$ de $\mathrm{P}_{2} \mathrm{O}_{5}$ solúvel em ácido cítrico. Soluções contendo cloretos de cálcio e potássio são subprodutos do processo (RAHAL et 
al., 1988).

e) $\mathrm{KCl}$ a partir de carnalita - tratando-se carnalita, $\mathrm{KCl} \cdot \mathrm{MgCl}_{2} \cdot 6 \mathrm{H}_{2} \mathrm{O}$, com amônia ou uréia, a temperatura menor que $100^{\circ} \mathrm{C}$, obtêm-se soluçōes com $\mathrm{KCl}$ e $\mathrm{NH}_{4} \mathrm{Cl}_{2} \cdot \mathrm{MgCl}_{2} \cdot \mathrm{nH}_{2} \mathrm{O}$ (amônia) ou $\mathrm{CO}\left(\mathrm{NH}_{2}\right)_{2} \cdot \mathrm{MgCl}_{2} \cdot \mathrm{nH}_{2} \mathrm{O}$ (uréia). $\mathrm{O} \mathrm{KCl}$ é separado da solução por cristalização seletiva e em seguida seco. A solução restante constitui fertilizante nitrogenado com magnésio (CEKINSKI et al., 1989).

- Os fertilizantes de solubilidade controlada podem representar excelente opção para solos de cerrado, como mostram experimentos em casa de vegetação para culturas de milho, sorgo, soja e eucalipto, quando comparados com fertilizantes solúveis em água do tipo fosfatos super triplo e cloreto de potássio (NEVES et al., 1987; BAILLIF et al., 1989).

\section{REFERÊNCIAS BIBLIOGRÁFICAS}

BAILLIF, P.; VALARELLI, J.V.; TOURAY, J.C. (1989) Étude comparative de la solubilité de deux verres silico-phosphatés d'interêt agronomique: donnés de l'analyse XPS. Comptes Rendus de P'Académie des Sciences Paris, 308(2):1135-1141.

CEKINSKI, E.; CALMANOVICI, C.E.; VALARELLI, J.V. (1989) Produção de KCl a partir da carnalita. Fertilizantes (IPT), 11,(1):6-7.

GUARDANI, R. (1982) Estudo do efeito da composição química, temperatura de processamento e velocidade de solidificação sobre a estrutura e solubilidade do termofosfato magnesiano fundido. São Paulo, 79p. (Dissertação de Mestrado - Escola Politécnica/USP).

GUARDANI, R.; VALARELLI, J.V.; CEKINSKI, E.; PEREIRA, S.C.C. (1985) Aproveitamento das rochas alcalinas de Poços de Caldas e fosfogesso na produção de fertilizantes potássicos e $\mathrm{SO}_{2}$. Fertilizantes (IPT), 7(2):4-8.

NEVES, J.C.L.; BARROS, N.F.; NOVAES, R.F. (1987) Avaliação de produtos alternativos dos fertilizantes químicos tradicionais como fontes de nutrientes e corretivo dos solos para as plantas. Relatório final FUNARBE/DOCEGEO, Univ.Fed.Viçosa, 82p. 
PEREIRA, S.C.C.; CEKINSKI, E.; VALARELLI, J.V. (1988) Process for production of calcined phosphate in a grate furnace. Fertilizer Research, 16:169-177.

RAHAL, F.G.; NEUMANN, R.; PEREIRA, S.C.C.; CEKINSKI, E.; CAMANOVICI, E.; VALARELLI, J.V. (1988) Desenvolvimento de processo de produção de fosfato de magnésio. Fertilizantes (IPT), 10(1):13-15.

VALARELLI, J.V. \& GUARDANI, R. (1981) Estudos experimentais para utilização das rochas potássicas de Poços de Caldas como fertilizante. Fertilizantes (IPT), 3(3):47. 